Open Access

\title{
Can flipped classroom enhance class engagement and academic performance among undergraduate pediatric nursing students? A mixed-methods study
}

\author{
Toqa Jameel Abbas Busebaia(D) and Bindu John ${ }^{*}$ (D)
}

\author{
*Correspondence: binduthycad@ \\ hotmail.com; bthycad@uob.edu.bh \\ Nursing Department, College of \\ Health Sciences, University of \\ Bahrain, P.O. Box. 32038, Sakeer, \\ Kingdom of Bahrain
}

\begin{abstract}
The study aimed to assess the nursing students' class engagement and academic performance using flipped class using a mixed-methods research and explored their feedback and perceptions about the flipped classroom (FCR) in comparison to the current teaching methodology. Participants were 22 females and 4 males, selected through convenience sampling method, and were evaluated at pre-cycle with casebased learning, post-cycle I with FCR, and post-cycle II, using FCR with an extra class time, in a cyclical nature of inquiry. Data collection involved a triangulation technique using checklists to observe and assess students' class engagement, quizzes for measuring class performance, and focus group interviews. The focus group interview reflections and feedback were used to refine and plan the next cycle.

The quiz and the class engagement scores were highly significant at post-cycle II where the FCR was used with extra class time compared to post-cycle I and pre-cycle. The participants stated that they gained a deeper understanding of concepts, were motivated and more confident in learning the course material. The study findings support the use of FCR in learning pediatric course content. Further empirical evidence is required for adapting FCR to other courses in the curricula to determine its suitability to a particular teaching content.
\end{abstract}

Keywords: Active learning, Class engagement, Collaborative learning, Nursing Education, Flipped classroom, Innovation

\section{Introduction}

Redesigning the learning experiences is an integral part of pedagogy and requires the nursing faculty to provide instruction by integrating problem-solving strategies and offering meaningful learning outcomes (Bernard, 2015; Mailloux, 2011; Rocca, 2010). This requires careful assimilation of relevant techniques to suit the learner-centered teaching practices, through using technology, simulation, gaming, narratives, art, reflection, and problem-based learning (Crookes, Crookes, \& Walsh, 2013; Rodrigues \& Zealand, 2016). Evidence-based teaching practices (EBTP) necessitate that nurse educators must move beyond the traditional instructional strategies and use explorative teaching methods supported by qualitative and quantitative research findings (Valiga, 2006). This also requires that the faculty should possess a profound understanding of

(c) The Author(s). 2020, corrected publication 2021. Open Access This article is distributed under the terms of the Creative Commons Attribution 4.0 International License (http://creativecommons.org/licenses/by/4.0/), which permits unrestricted use, distribution, and reproduction in any medium, provided you give appropriate credit to the original author(s) and the source, provide a link to the Creative Commons license, and indicate if changes were made. 
educational theories and researches to implement learner-centered teaching models, to bring the most appealing results, and to address the perceived barriers associated with its implementation (Bernard, 2015).

One of the commonly adopted teaching methods in teaching professional education systems is case-based learning (CBL). CBL is an instructional design that involves an interactive, student-centered, contextualized learning exploration of realistic and specific situations and can include fictional, virtual, or simulated cases (Thistlethwaite et al., 2012). CBL is widely used in higher education, across the curriculum of Bachelor of Science in Nursing Program in our institution over various courses. In CBL, students apply their knowledge to real-world scenarios, promoting higher levels of cognition, by working in groups in classes, intended to devise solutions under the guidance of the instructor (Herreid, 2011). CBL is considered to be a highly effective method which facilitates small group learning (Bonney, 2015; Herreid \& Schiller, 2013), increases critical thinking, makes better connectedness across multiple content areas, and helps to better grasp of practical applications of core concepts (Bonney, 2015). But, it also demands extensive preparation and collaborative group work by the students, and cooperation of the participants as well as requires high analytical skills of the data to generate possible solutions (Herreid, 2007). Concerns were raised about the lack of preparation time by the participants and the faculty, lack of relevant case studies, and the challenges faced by the students due to complex, poorly understood cases, with insufficient advice available to the instructional designers for every kind of problem to be solved by a case (Jonassen \& Hernandez-Serrano, 2002; Yadav et al., 2007).

Flipped classroom method has emerged as one of the innovative means of effective teaching for undergraduate nursing students and has the potential to change teaching and learning for nursing education (Hessler, 2016). Flipped classroom is a hybrid or a blended approach to learning in which the direct classroom lecture is moved to a "homework" status or outside the classroom teaching, through online, video-recorded lectures made available to the students (Missildine, Fountain, Summers, \& Gosselin, 2013). Thus, the group learning space in the classroom is transformed into a dynamic, interactive learning environment, in which the instructor guides his/her students to acquire a deeper level of application of core concepts and subject, creatively and interactively (Bergmann \& Sams, 2012; Hessler, 2016; Missildine et al., 2013). A flipped classroom (FCR)-based teaching approach integrates students' significant pre-class preparation, including watching pre-recorded lecture materials, posted online to watch on their own before class, with the utilization of class time for student-centered learning activities such as discussion and/or problem-solving for relevant topics or inquiryoriented strategies (Tang et al., 2017). More specifically, it replaces the standard lecture-in-class format with interactive learning opportunities and can complement the CBL. FCR has the advantage of providing a variety of learning experiences appropriate for each student (Bergmann \& Sams, 2012), with organized interactive encounters in classrooms, providing challenging creative thinking in students, promoting novel exposures of learning through collaborating, expert insight and feedback (Bergmann \& Sams, 2012). Students can master the content and comprehend the class material before coming to the class so that they participate in the class discussion. FCR has transformed many traditional classrooms into dynamic, in-class active learning classrooms by stimulating higher-order thinking in students through the use of applied learning 
strategies and creative technologies (Blouin et al., 2009; Blouin, Joyner, \& Pollack, 2008; McLaughlin et al., 2014).

Flipping the classroom creates an ideal mix of online and face-to-face instruction that is becoming known as a "blended" classroom (Bergmann \& Sams, 2012). Previous research including a meta-analysis conducted in the nursing education field provides evidence that an FCR can significantly improve academic performance both in practical understanding of the subject matter knowledge, self-learning abilities, critical thinking, and problemsolving skills compared with traditional lecture (Hung, 2015; Tan, Yue, \& Fu, 2017; Tang et al., 2017; Unal \& Unal, 2017). FCR also showed that it fosters team learning ability in students (Sojayapan \& Khlaisang, 2018). Although FCR is relatively a new approach in teaching and supporting a student-centered, active-learning approach, with improved academic performance in students, class attainment, greater participation, and a perspective toward learning, quantitative research of student outcomes based on a flipped classroom is very limited (Harrington, Bosch, Schoofs, Beel-Bates, \& Anderson, 2015), particularly in the field of nursing education (Bernard, 2015; Panicker, 2018).

Case-based learning is still one of the most popularly used methods and active learning strategies for nursing curricular instruction in Arab countries, as well as Gulf regions. Even though a few studies have been published with regard to the implementation of FCR in subjects like English (Al-Harbi \& Alshumaimeri, 2016; Khalil, Rania, \& Fahim, 2017), Arabic language (Al-Harbi \& Alshumaimeri, 2016; Jwaifell, Abu-Omar, \& Al-Tarawneh, 2018), mathematics (Diab \& Abdel, 2016), social work, environment systems and societies (Wagner, 2018), and physics (Atwa, Din, \& Hussin, 2018) in Arab and Gulf countries, to our knowledge, no studies so far have tested the use of FCR among nursing students.

The present study aimed at assessing the nursing students' class engagement and academic performance using flipped class (FC) and exploring their feedback and perceptions with regard to FC compared to the current teaching methodology using a mixed methods action research (MMAR). Action research (AR) approach is often used in educational research, and it integrates teaching and learning by using a participatory process for developing a practical knowledge for solutions to issues of significance (Kemmis, McTaggart, \& Nixon, 2013). AR is defined as "a process in which participants examine their own educational practice systematically and carefully using the techniques of research" and primarily meant for educational improvement (Ferrance, 2000; Nugent, Malik, \& Hollingsworth, 2012). The "action" in the research can involve assessment of a process being used or affirmation of a change over time, both of which necessitate clear data collection processes (Moch, Vandenbark, Pehler, \& Stombaugh, 2016). AR is conducted by the researchers using the following steps involving a cyclical nature of inquiry: plan, act, observe, and reflect (Kemmis et al., 2013). It is an ongoing process by which the researcher uses repeated steps or cycles continuously in a learning situation for continuous improvement in classroom instruction (Biggs, 2011; Nugent et al., 2012). The AR phases are based upon one another in a spiral nature of the action, and subsequent cycles built on the reflection of the previous cycle (s) (Glenda Nugent, Malik, \& Hollingsworth). An AR was chosen in this study because there was a significant challenge faced by the nurse educators while using the current practice of lecturing combined with CBL with regard to the class engagement and academic performance of students, in the pediatric nursing course offered in their fourth year of 
study and also a high rate of low grades. Researchers suggest that the validity of AR depends on the ability to deal with a practical problem in the researcher's organization (Dickens \& Watkins, 1999).

\section{Research questions}

1. How effectively can the FCR help in enhancing the class engagement and academic performance of nursing students compared to the CBL?

2. To what extent do the nursing students perceive the use of and learning with an FCR compared to the current teaching methodology?

\section{Methods}

The study used an AR methodology using both quantitative and qualitative approaches (mixed method AR using a triangulation technique) to measure the impact of the FCR method and to understand their perceptions in using this learning method. The study was conducted as a part of the postgraduate certificate for academic practice program (PCAP) at the researcher's institution. The study was approved by the Scientific Research Ethical Committee of the researcher's institution BADA/2016/97 dated on the 5th of May 2016.

A non-probability, the convenience sampling method was used in this study. Participants were 26 students in the age group of 21-24 years, enrolled in the fourth year of the baccalaureate nursing program. In addition, a small group of five students was selected from the same group for the focus group feedback interviews for collecting the qualitative data information. All male and female students enrolled in the pediatric course in the current semester in one section with the researcher and who are willing to participate in this study were included. The participants were excluded if they were not enrolled in that section and if they were not willing to participate in the study. A convenience sampling with a small sample size was chosen in this study because in an AR, the main goal is to improve one's own teaching practice (Andrew \& Johnson, 2012). The participants' number is often limited, or a small sample size may be eligible or probably needed for the focus of investigation (Efron \& Ravid, 2013). Practical considerations to what can be done within your time limit is a factor in the decision to determine the criteria criteria of selection (Efron \& Ravid, 2013). Moreover, once the course material is uploaded online, all students can access it, or they could share it; thus, a random sampling may not be practically feasible in this particular situation. Both verbal and written consent were obtained from the students who agreed to participate in the study.

The study was carried out in three phases, pre-cycle, post cycle I, and post cycle II, with a cyclical nature of inquiry. The data was collected from the 13th of February 2018 to the 12th of March 2018. The data collection techniques utilized for the triangulation approach in this AR process were observation using checklists, quizzes for measuring the class performance, and focus group interviews. According to the literature, compiling multiple sources of data collected in systematic ways from numerous sources at different stages of the project provides an evidence base to make interpretations and statements in a triangulation technique, as well as to increase the validity and confidence of the research findings (Ferrance, 2000; Nugent et al., 2012). The outcomes 
were measured during and at the end of each cycle. The focus group feedback interviews served as a motive to plan and refine the procedure for the next cycle.

Since AR, unlike the traditional research, focuses on candidates in researchers' own setting, the focus of inquiry was one group of participants in the researcher's classroom; and thus, a power analysis was not performed in this study. Power analysis is closely linked to hypothesis testing, and in AR, and the researcher is not trying to support or disprove the hypothesis (Andrew \& Johnson, 2012). A small sample size may be eligible or probably needed for the focus of investigation (Efron \& Ravid, 2013; Nugent et al., 2012).

\section{Instruments for data collection}

The following tools were employed in data collection:

1) Student Class Engagement Checklist: The observation checklist used to measure the class engagement of students was developed with an extensive review of literature and in consultation with the senior faculty members who were involved in teaching the course in previous years, as well as the subject experts in this field who checked the content validity of the items. Three domains of students' class engagement were assessed: scholastic instruction, team and share learning, and learner-teacher interchange. There were a total of nine items in the checklist, with each response scored either as "Yes" or "No." If the total score is from $0-3$, the engagement is considered as low. The medium and high-class engagement was given the ranges of 4-6 and 7-9, respectively.

2) Quizzes: Quizzes (Karabulut-Ilgu, Cherrez, \& Hassall, 2018; McLaughlin et al., 2014; Peisachovich, Murtha, Phillips, \& Messinger, 2016) and post-tests (Tang et al., 2017) are frequently used methods for assessing academic performance in FCR models. In this present study, a 10-item multiple choice questions (MCQs) were constructed to assess the students' academic performance of short-term retention of class information and were based on the session learning outcomes. It assessed the students' ability to analyze the given situation as well as to apply the knowledge learned through online materials and in-class activities. The total score of the quiz was 10 and would contribute to their academic knowledge of the content taught. The scores of the quiz were categorized as A (scores from 9-10), B (scores from 7-8), C (scores from 5-6), and F (for scores below 5). The MCQs at each cycle were constructed with the same level of complexity, using some higherorder thinking level questions, such as analyzing and application types. Few of those questions have been measured in the previous exams using item analysis, which had been used as a tool of reliability to measure the complexity of questions at each cycle. The content and face validity of the prepared quizzes were checked by the expert pediatric nursing faculty at the researcher's institution. The appropriateness and relevance of the content and its representativeness to measure the specific topic area was evaluated with the sample of questions constructed (Polit \& Beck, 2008).

3) Focus group semi-structured interview questionnaire: A semi-structured interview questionnaire was used to elicit the participants' perception of the use of FCR compared to the current teaching methodology. The questionnaire included six 
descriptive items about the method of learning. The students were asked to share their viewpoints until the data saturation point was reached and no more themes were encountered, and the comments were utilized for the revision of the forthcoming cycle of AR.

\section{Phases of the AR cycle and data collection}

Prior to the data collection, an information letter was distributed to the study participants in the classroom with details pertaining to the aim of the study, researcher's identity, benefits of participation, assurance of confidentiality, right to participate and withdraw from the study, and the means of obtaining the study results. Verbal and written consent was obtained from the students. All questionnaires were coded prior to distribution.

Data were collected at three consecutive phases: the pre-cycle, post cycle I, and post cycle II. Figure 1 illustrates the details of the procedure followed in the three cycles. Outcomes were measured during and at the end of each class session, using students' class engagement checklist and quizzes. The qualitative data collection was carried out using focus group interviews, which was conducted with five nursing students in the meeting room, who volunteered to give information at the end of the day following the class session, following each cycle, and lasted for 90-120 min. The principle used for guidance in the interview was data saturation, which occurs when themes and categories in the data become repetitive and redundant, and no more new information can be extracted by further data collection (Polit \& Beck, 2008). All the interviews were taperecorded. All the data files and the audio-tapes were kept under a safe locker to maintain the confidentiality of information supplied by the participants.

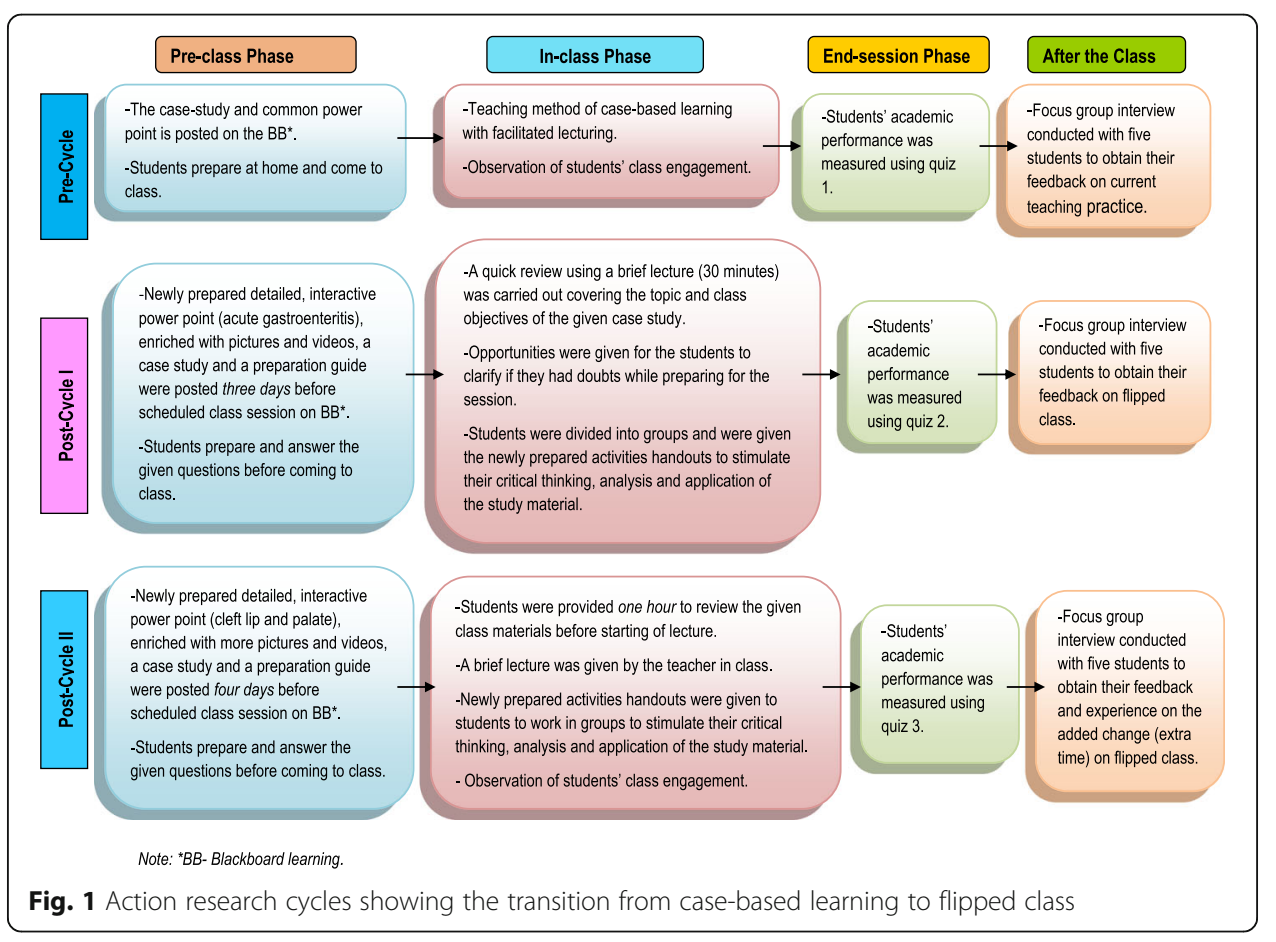


During the pre-cycle, the researcher carried out the usual CBL in the classroom while the students are discussing/answering questions pertaining to the case (bronchopneumonia) and related tasks with a facilitated lecture by the teacher for describing the pathophysiology, clinical manifestations, and the diagnostic tests. The case study pertaining to the case and the power point presentation of the particular topic was posted on blackboard learning (BB) well ahead at the beginning of the semester. During the class activity, the class participation of the students was observed by the researcher using the student class engagement checklist. At the end of the class session, a quiz was introduced and the academic performance was measured. Following the class, a focusgroup interview was conducted to gain an overall experience of the students' perception and feedback about the current teaching methodology. The high rate of failing grades obtained in the quiz, with a low level of class engagement and interaction during group work, and the suggestion by the focus group feedback for making the class interesting made the researcher introduce the next cycle.

During the post-cycle I, the FCR was introduced. The interactive power points (for the topic acute gastroenteritis) with detailed pictures and illustrations along with the case study and preparation guide were posted in the BB 3 days before the intended class session, during the weekend. The students were expected to prepare before they come to the class. The teacher did a quick and brief review of the topic in the class for $30 \mathrm{~min}$, and the students were given an opportunity to clarify any doubts regarding the session. A group activity followed the class and handouts were distributed to the students which facilitated in-depth review and discussion of the study material. Quiz, observation of the students' class engagement using the checklist, and focus group interview were carried out like in pre-cycle. The focus group feedback about the lack of time to prepare before coming to the class by going through the materials and organizing their thoughts, along with the researcher's observations of students' participation in the class, inspired the researcher to go to the next cycle.

During the post cycle II, the researcher gave students $1 \mathrm{~h}$ of the official class time (within the credit hours of the subject) to review the class materials for the topic cleft lip and palate, which was posted in the BB 4 days including the weekend, before the intended class session. A brief session highlighting the main points of the topic was done by the teacher. The activities' handouts were given to the students who were in groups, and an in-depth review and discussion of the study material were carried out like the post cycle I. Observation of class engagement, quiz, and focus group interview was carried out similar to other cycles.

The details of various cycles and phases of AR showing the transition from CBL to flipped class are shown in Fig. 1.

\section{Data analysis}

The analysis of the quantitative data was carried out using SPSS version 20. Mean, standard deviation, frequencies, and percentages were used to measure the academic performance and class engagement. A Friedman test was carried out to compare the effect of FCR on academic performance and students' class engagement between various cycles. The level of significance was set at $p^{<} 0.5$. 
The qualitative data from the focus group feedback was analyzed using a content analysis methodology (Erlingsson \& Brysiewicz, 2017; Graneheim \& Lundman, 2004). The qualitative content analysis objective is underlined in the systematical transformation of a large amount of text into a highly organized and concise summary of key results (Erlingsson \& Brysiewicz, 2017). The researchers, after gaining an overall understanding of the discussion, divided the text into meaning units and condensed the data. Labeling condensed meaning units was done next followed by formulating the codes and grouping the codes into categories for reporting results. Themes were then formed to express the underlying meaning in the categories. Three major themes were evolved from the interviews: the teaching method, a revolution and an experience; the didactic materials, for entertainment and information; and esprit de corps, the in-class activities and interactions.

\section{Results}

A total of 26 students ( 22 females and 4 males) participated in the study. Three cycles of AR were introduced between the 13th of February 2018 and the 12th of April 2018 to the students in the class during the pediatric nursing course.

\section{Quiz scores}

During the pre-cycle, $53.8 \%$ failed in the quiz and the remaining $46.2 \%$ got $\mathrm{C}$ grade. During the post-cycle, I, majority of the students $(n=13,50 \%)$ obtained a B grade, and 10 of them scored A grade (38.5\%). In the post-cycle II, the majority of the students scored A grade $(n=12,46.2 \%)$ and 9 of them obtained B grade (34.6\%). Table 1 summarizes the quiz scores obtained by the students in various cycles of AR.

\section{Student class engagement scores}

In the pre-cycle phase, the majority of the students $(n=15,57.7 \%)$ obtained a low classengagement score and $7.7 \%$ of them $(n=2)$ obtained a high-class engagement score.

In the post-cycle I, majority of the students' class engagement scores was high $(n=13$, $50.0 \%$ ), and $7.7 \%$ of them received a low-class engagement score. In the post-cycle II, the majority of the students $(n=23,88.5 \%)$, received a high class-engagement score (Table 1$)$.

Table 1 Scores obtained for students' class engagement and academic performance at various cycles of action research

\begin{tabular}{llll}
\hline Grade & Pre-cycle & Post-cycle I & Post-cycle II \\
\hline Student engagement in class & & & \\
High engagement & $n=2,7.7 \%$ & $n=13,50.0 \%$ & $n=23,88.5 \%$ \\
Medium engagement & $n=9,34.6 \%$ & $n=11,42.3 \%$ & $n=3,11.5 \%$ \\
Low engagement & $n=15,57.7 \%$ & $n=2,7.7 \%$ & $n=0,0.0 \%$ \\
Academic performance in class & & & \\
Grade A & $n=0,0.0 \%$ & $n=10,38.5 \%$ & $n=12,46.2 \%$ \\
Grade B & $n=0,0.0 \%$ & $n=3,11.5 \%$ & $n=9,34.6 \%$ \\
Grade C & $n=12,46.2 \%$ & $n=0,0.0 \%$ & $n=0,19.2 \%$ \\
Grade F & $n=14,53.8 \%$ & & $n=0.0 \%$ \\
\hline
\end{tabular}




\section{Effect of the flipped classroom on student engagement and academic performance}

The effect of the flipped classroom on student class engagement and academic performance was determined by comparing the mean scores obtained at different cycles using a Friedman test. A significant difference between the mean scores obtained for the quiz at post cycle II compared to post-cycle I and pre-cycle was obtained $(M=8.0$ $\pm 1.6, M=7.8 \pm 1.2$, and $M=4.3 \pm 1.3$ for post-cycle II, post-cycle I, and pre-cycle, respectively, $p^{<}$0.001).

Similarly, Friedman test carried out for determining the efficacy of the student class engagement demonstrated a significant difference between post-cycle II, in comparison with post-cycle I and pre-cycle phases of AR $(M=7.8 \pm 1.4, M=6.4 \pm 2.0$, and $M=$ $2.7 \pm 2.6$ for post-cycle II, post-cycle I, and pre-cycle, respectively, $p<0.001$ ).

\section{Focus group feedback findings}

The focus group feedback at pre-cycle, post-cycle I, and post-cycle II was classified under the following themes: the teaching method, a revolution and an experience; the didactic materials, for entertainment and information; and esprit de corps, the in-class activities and interactions. The various responses by the students on each of these category themes at various cycles are summarized in Table 2 .

\section{Discussion}

This study aimed at assessing the nursing students' class engagement and academic performance using flipped class (FC) and to explore their feedback and perceptions with regard to FC compared to the current teaching methodology using a mixed methods action research (MMAR). Our study results revealed that the students reacted positively to FCR applied to teaching and learning in the pediatric nursing course, in comparison to the CBL method.

FCR is one approach which can be tailored according to the learners, resources, and time at any educational level and engages the student in active learning within the limited class time by utilizing it for more collaborative activities under the supervision and direction of the instructor (Berrett, 2012; Milman, 2012). Andrews, Leonard, Colgrove, and Kalinowski (2011) affirms the learner's active role is a remedy for many of the learning difficulties experienced by undergraduate students, especially those pertaining to understanding fundamental concepts and to overcome their passive roles. Active learning is further supported in literature with the use of motivational and selfregulatory strategies across different tasks and contexts, to suit the students' learning styles, contributing to in-depth understanding and predicting students' academic performance (Richardson, Abraham, \& Bond, 2012).

The students' engagement in class showed significant differences when using FCR provided with extra time compared to FCR alone and using CBL learning. It could be that the FCR approach focuses on creating learning environments that support students to be the center of the learning process. It is natural that they feel more competent when they are given an opportunity to be in charge of the dissemination of knowledge through active participation than being passive recipients (Abeysekera \& Dawson, 2015). The students were more confident and were able to adapt to their own learning style when FCR was employed, and the discussion in class helped them to collaborate 
Table 2 Summary of findings from the focus group feedback with the major themes evolved

\begin{tabular}{|c|c|c|c|}
\hline $\begin{array}{l}\text { Themes } \\
\text { classification }\end{array}$ & Pre-cycle & Post-cycle I & Post-cycle II \\
\hline $\begin{array}{l}\text { Theme 1-The } \\
\text { teaching method: } \\
\text { a revolution and } \\
\text { an experience }\end{array}$ & $\begin{array}{l}\text { Most of the students stated } \\
\text { that CBL requires a lot of } \\
\text { preparation, and they do not } \\
\text { have sufficient background } \\
\text { to contribute more to it. } \\
\text { They were hesitant of } \\
\text { contributing wrong things. } \\
\text { Students stated expressed } \\
\text { that they are used to this } \\
\text { CBL method and it is no } \\
\text { more interesting. Instead, } \\
\text { they preferred to have a } \\
\text { method by which they can } \\
\text { learn better and they can } \\
\text { participate in an interesting } \\
\text { way. }\end{array}$ & $\begin{array}{l}\text { Students commented that } \\
\text { FCR is very interesting. } \\
\text { Preparation for the class from } \\
\text { home was easier than before, } \\
\text { and they said that they felt } \\
\text { like attending the lecture in } \\
\text { the class. } \\
\text { Students felt the advantage } \\
\text { of using the FCR method is } \\
\text { that they could use it at their } \\
\text { pace. They appreciated the } \\
\text { brief review of the case in } \\
\text { the class, as it made the } \\
\text { concept clearer and helped } \\
\text { in the retention of } \\
\text { information. }\end{array}$ & $\begin{array}{l}\text { The students reacted that } \\
\text { the additional one hour of } \\
\text { preparatory time before the } \\
\text { class helped in in-depth } \\
\text { reviewing the learning mate- } \\
\text { rials and to organize their } \\
\text { ideas. } \\
\text { The students felt that the } \\
\text { extra time helped in } \\
\text { clarification and discussion of } \\
\text { points with their peer group } \\
\text { members and they felt } \\
\text { better guided with the } \\
\text { presence of the teacher. } \\
\text { They appreciated that it } \\
\text { helped them in getting } \\
\text { better scores in quizzes. }\end{array}$ \\
\hline
\end{tabular}

Theme 2-The Students commented that didactic materials: the source of information in for entertainment CBL is the prescribed and information

Theme 3-Esprit de corps: the inclass activities and interactions textbook and the PowerPoint material in BB. Some of the information in the textbook is not clear as they are not exposed to the cases. Students felt that there is very less information in the power point and are not suitable for discussion and it is boring. They preferred to have some information which stimulates their learning.

Students expressed that the sequence of activities is always the same in $\mathrm{CBL}$, and there are some students who will not prepare and willing to present in the class. They suggested having more teamwork for making better interactions.

The students perceived that the case given may not be covering all areas of the disease condition. They encounter problems with limited information while answering the questions during the discussion. They expressed to have detailed activities covering the entire topic.
Students considered the power point in the FCR as very interesting and self-

explanatory. They commented that it was very appealing with videos and animation, and was a very rich experience.

The students regarded the information as a bit overwhelming, even though interesting as they have also other subjects to learn. They expressed to have more time for class preparation and for solving the questions.

The students rated the class activities in FCR very interesting and viewed that all students could actively participate in it.

The students regarded that the discussion in the class was better than the presentation, about various aspects of the case, as all the students could get involved and concentrate. They suggested having added varieties of activities to encourage further interactions in smaller groups.
The students reported that the power points with plenty of diagrams were extremely helpful and made the concept very clear. The detailed information made clarification of the topic better and stimulated their critical thinking as well as to organize their ideas and to get ready for answering the questions.

The students said that they could visualize their role as a future nurse while doing the activities, especially when it came to role playing and discussion.

The students expressed a clearer understanding of the concept and conveyed that they were very motivated to participate in class activities. They also felt very confident to answer any question and to contribute to each other in discussion and said that the quiz was really helpful to gain a better understanding of the session.

Note: $C B L$ case-based learning, $B B$ blackboard learning, $F C R$ flipped classroom

the ideas and generate a better, clearer understanding of the course content. Panicker (2018) reported that FCR increased the engagement of students in various tasks in the nursing research course and eventually reflected in higher academic performance. In a case study describing where the FCR model was applied, she also reported that it enhanced the students' participation and helped to create an online community of learning supported by the formative feedback. Motivating students and encouraging in-class activities and providing stimulating class environment created better student 
interactions and the probability of gaining insight from the learning experience which would have resulted in improved student outcomes (Davey, 2015; Panicker, 2018).

In our study, we used in-class quizzes to test the knowledge students gained in learning the content, in contrast to Rodrigues and Zealand (2016) for the clinical learning curriculum of nursing students, where online quizzes were used to better understand the class session. But, similar to those results where the FCR model enhanced the clinical learning skills, our study results also gave better scores when the FCR model was used, compared to the usual CBL method. Quizzes can be employed as a method to test the students' comprehension by the teacher, measuring the students' understanding of the class material. Bergmann and Sams (2012) pointed out that the use of videos and quizzes as powerful instruments for the teachers help to share, build content, and refine practice. Similarly, in a study conducted by Tune, Sturek, and Basile (2013) as well as by Peisachovich et al. (2016), FCR with frequent quizzes were found to be highly effective for better students' performance in the physiology course and in health assessment course, which was similar to our study results. But interestingly, a study conducted among the nursing students in pharmacology course by El-Banna, Whitlow, and McNelis (2017) did not demonstrate a significant difference in the academic performance of students when the FCR was applied compared to the traditional lecture-based instruction. Lower academic results were reported by the students who used digital materials without interaction and class activities with peers and lecturers in a study conducted by Johnston, Massa, and Burne (2013). This means that adult learners should choose the best learning options to support their academic learning.

The results from the qualitative analysis evolved through focus group feedback gave an insight into the students' learning approaches and in-class activities. Students had a high preference for the FCR model and were more stimulated to become active in learning compared to the pre-cycle session and that was evident from their responses. Increased understanding of the concepts and its application to clinical practice and promoting a deeper and wider thinking among students were perceived to be the positive outcomes of using FCR that combined e-Lecture prior to the class with face-to-face interaction in the classroom, in a study conducted among nursing students in pharmacology course (Hanson, 2016). Learner empowerment, social learning, and emancipating flexible, lifelong learning are some of the key features focusing on the future pedagogical ideas, where the learner applies knowledge through intellectual inquiry in professional and applied contexts (Ryan \& Tilbury, 2013). In contrast, more satisfaction using the traditional lecture method compared to FCR is reported in a study carried out among nursing students (El-Banna et al., 2017). This is probably due to the course in which it was applied, the pharmacology, where the students did not have a prior understanding or foundational knowledge in the subject and perceived FCR as overwhelming. It should be taken into consideration that the FCR requires the student to do some pre-class preparation, to develop a pattern for his or her own strategy of learning, and to obtain better results. Moreover, careful consideration of the rationale in implementing the FCR approach should be applied prior to its implementation (Bergmann \& Sams, 2012; McLaughlin et al., 2014).

Similar to the study results by Peisachovich et al. (2016), Chan, Lam, and Ng (2018) and Tang et al. (2017), our students also have voiced out as a concern and 
complaint about the amount of preparation time they needed to employ this method in order to listen to the online lectures, complete the reading for in-class interactive session, and complete the assignments. They were benefited from the 1$\mathrm{h}$ extra preparation time provided to them in the post-cycle II, before starting the class. However, our overall experience with FCR suggests that when the classroom becomes more student-centered, with utilization of instructor contact time for higher-level intellectual activities such as concept integration, communication, critical and creative thinking, problem-solving, and practical application of knowledge, this will bring improved learning outcomes, through increased student-instructor and peer-peer interactions (Blouin et al., 2008; Rodrigues \& Zealand, 2016). It might be helpful if we use FCR in higher classes, in particular to those enrolled in senior-level professional degree courses, because such students will be more accustomed to manage their time effectively in comparison to the novice learners who are still adapting to their studies and the new college life.

Our study results on the role of FCR to promote an understanding and application of key concepts, and increasing students' confidence was similar to the study results by McLaughlin et al. (2014), where more than $90 \%$ of the pharmacy students agreed that learning materials and resources in FCR was very helpful and the instructional method enhanced their learning. In contrast, employing FCR in teaching nursing management course in Brazil elicited mixed results, partially because the students did not perform the reading or proposed activities (Menegaz, Dias, Trindade, Leal, \& Martins, 2018). Similar to those results, inappropriate use of the flipped methodology has been identified as one of the factors for its low acceptance during its introduction in the pharmacy course among undergraduate students in Malaysia (Chan et al., 2018). It is a fact that FCR brings about a challenge and change from the traditional role of the teacher and learner. Learning is most effective when the learner is actively involved in understanding the application of content (Rodrigues \& Zealand, 2016), which is the principle used in FCR. Studies suggest that FCR may not be appropriate or effective for every subject matter and could be more suited to the materials in which there is practical or hands-on training (El-Banna et al., 2017; Roehling, Root Luna, Richie, \& Shaughnessy, 2017), but our experience was different. The interactive class materials, case studies along with the use of self-reflection, debates, and teamwork help the students to explore the attitudes and values of the learning content and motivate the learner to develop higher-order thinking skills (McLaughlin et al., 2014). The success of a FCR depends on optimizing the learning spaces within the classroom by giving students a control over their learning by the teachers, collaboration between the students, adequate time for implementation, support from the administrators, and access to the information technology, and a thoughtful reflection and trust between students and teachers to fulfill the obligations to each other (Bergmann \& Sams, 2012). It requires sustained motivation and contribution before, during, and after live instruction (Rodrigues \& Zealand, 2016).

Role playing carried out in the post-cycles I and II in our study can be viewed as a simulation exercise, in which students assume roles to act out a scenario, perceive the underlying emotions, experience the scenario from another student's point of view, understand, and relate it to the content to be learned (Kumar, 2011). FCR 
enriches and supports the use of diversified learning styles using mixed abilities from a student-focused, didactic classroom, instruction, and assessments, facilitating learning through practical work and solving predetermined tasks (Wallace, 2013). The role play can be an energizing experience with a fun activity for the students when the interplay of key concepts can be turned into a realistic experience (Towle \& Breda, 2014). Moreover, it has the advantage of strengthening and promoting all domains of learning, including cognitive, psychomotor, and affective (Kumar, 2011).

Our study did not consider the quiz grades for academic achievement as part of the final grade. It was simply because of the fact that this methodology was applied only to one section of the pediatric nursing course, while other sections continued with the usual CBL method. Moreover, prior studies indicated an increased burden when learning in FCR (El-Banna et al., 2017), and we did not want the students to feel the same while implementing it in our course.

\section{Study limitations and recommendations}

The study is based on a small sample size and was limited to one university class led by the researcher, as it was an action research. Therefore, its applicability to other settings has to be based on assimilating factual evidence and the contextual similarity to transfer the findings. We used self-developed tools and not standardized tools for measuring students' class engagement. We also could not measure the students' final exam scores and compare them with the groups who did not take the flipped class to see if it had really produced a change in the overall achievement of the course outcomes. Future research is needed to improve and strengthen this area and also could employ a control group for comparison for the non-FCR teaching method, as well as for measuring the students' satisfaction with this method. However, we hope that this study would encourage those who are in the nursing and health-related education fields to replicate in their settings.

\section{Conclusion}

The individual student learning is unique and determines what and how they learned and is the most important aspect in the curriculum by which a learner is assessed (Biggs, 2011). Our present study results support the use of FCR for enhanced learning and revealed that it result in superior learning outcomes and enhance students' retention of knowledge, augmenting critical thinking and reflective practice in pediatric nursing course. Our study results provide evidence that using a combination of the approaches such as pre-class activities, self-paced video lectures, and post-class activities provides an effective strategy for the learner to better grasp the learning material. This especially suits the students in the modern world, who are by birth, the digital natives (born in an era when the digital technologies are already in full swing) (Hessler, 2016). However, it has to be understood that FCR should be carefully chosen while implementing it to any course or curricula, and the content matter should be considered in which it can be applied. Time available for pre-reading of the session, number of students, the amount of class material to be covered, faculty competence in effective planning of session, instructor training, and preparation time available should be weighed to determine its suitability while it is implemented. 


\section{Box 1 Contribution of this paper}

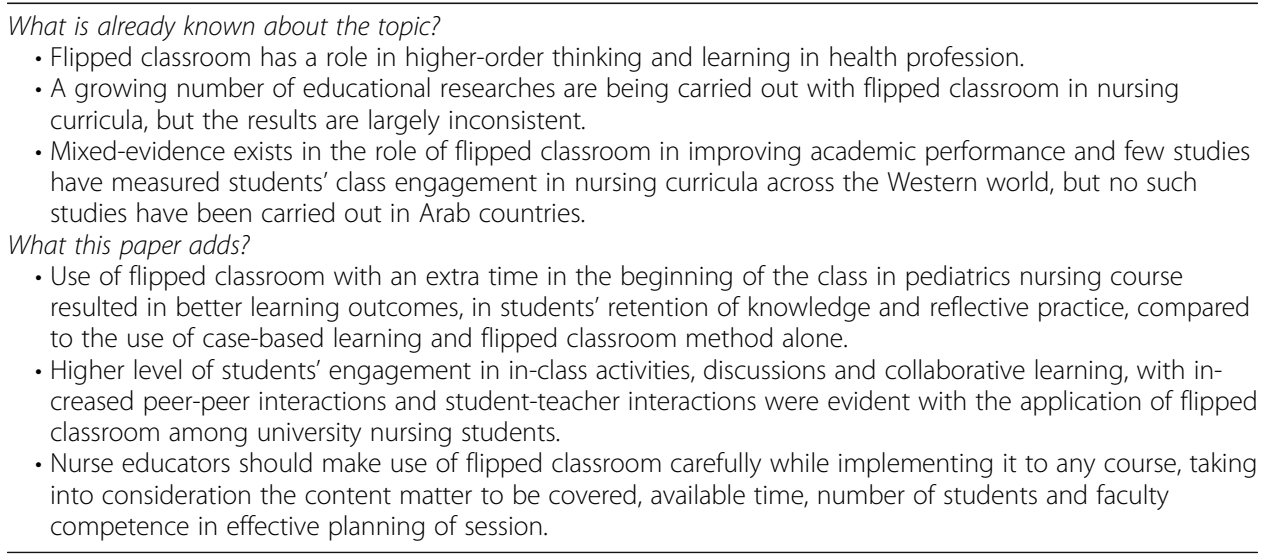

\section{Abbreviations}

AR: Action research; CBL: Case-based learning; EBTP: Evidence-based teaching practices; FC: Flipped class; FCR: Flipped classroom; MCQs: Multiple choice questions; MMAR: Mixed-methods action research; PCAP: Postgraduate certificate for Academic Practice Program

\section{Acknowledgements}

We would like to thank Ms. Muyassar Sabri, Coordinator, BSN Program, in our college and all the students who participated in this study. We would like to extend our appreciation towards Mr. Hassan Al Basri, Consultant Ex-statistician, College of Health Sciences, for the statistical analysis in the study. We would extend our sincere gratitude towards Mr. Hassan Al-Wadi, Assistant Professor, English department, University of Bahrain, for his guidance and support in this project. We express our appreciation towards Mr. Hamza S. Ahmed Hussain Al-Sadadi, Instructor, and Ms. Narjis Ahmed Salman, Lecturer, English department, College of Health Sciences, University of Bahrain, for their support in this project and for their effort in English Language editing of this paper.

\section{Authors' contributions}

TJ was the lead author who planned and implemented the study in close collaboration with BJ. TJ and BJ carried out the literature search. TJ contributed substantially to data collection and collaborated in data analysis and interpretation of results with BJ. BJ provided support for the study as an expert in the research field. BJ drafted the manuscript and both authors revised the draft in all stages of finalization. Both TJ and BJ read and approved the final manuscript.

\section{Authors' information}

Ms. Toqa Jameel Abbas Busebaia is a lecturer at the College of Health Sciences, University of Bahrain, and has been teaching courses like pediatric nursing, health promotion, and adult health nursing. She earned a Master's degree from the Royal College of Surgeons of Ireland in 2012 and a fellow from the UK Higher Education Academy (FHEA) in 2018. Dr. Bindu John is a lecturer at the College of Health Sciences, University of Bahrain, and has special research interests in sleep, adolescents, education and technology in nursing and health promotion. She earned a PhD in Nursing from Nitte University, India, in 2017 and M.Sc. in Community Health Nursing in 2002 from Dr. M.G.R Medical University, India.

\section{Funding}

Not applicable.

\section{Availability of data and materials}

Not applicable.

\section{Competing interests}

The authors declare that they have no competing interests.

Received: 25 June 2019 Accepted: 23 January 2020

Published online: 17 February 2020

\section{References}

Abeysekera, L., \& Dawson, P. (2015). Motivation and cognitive load in the flipped classroom: definition, rationale and a call for research. Higher Education Research \& Development, 34(1), 1-14.

Al-Harbi, S. S., \& Alshumaimeri, Y. A. (2016). The flipped classroom impact in grammar class on EFL Saudi Secondary School Students' Performances and Attitudes. English Language Teaching, 9(10), 60-80.

Andrew, P., \& Johnson, B. (2012). A short guide to action research. Mankato: Minnesota State University.

Andrews, T. M., Leonard, M. J., Colgrove, C. A., \& Kalinowski, S. T. (2011). Active learning not associated with student learning in a random sample of college biology courses. CBE - Life Sciences Education, 10(4), 394-405.

Atwa, Z. M., Din, R., \& Hussin, M. (2018). Effectiveness of flipped learning in physics education on Palestinian high school students' achievement. Journal of Personalized Learning, 2(1), 73-85. 
Bergmann, J., \& Sams, A. (2012). Flip your classroom: Reach every student in every class every day. International society for technology in education.

Bernard, J. (2015). Nurse educators' transition to flipped classroom: An interpretive description study. (Doctoral dissertation). Retrieved from http://dc.etsu.edu/etd/2603.

Berrett, D. (2012). How 'flipping' the classroom can improve the traditional lecture. The chronicle of higher education, 12(19), 1-3.

Biggs, J. B. (2011). Teaching for quality learning at university: What the student does. UK: McGraw-Hill Education.

Blouin, R. A., Joyner, P. U., \& Pollack, G. M. (2008). Preparing for a renaissance in pharmacy education: the need, opportunity, and capacity for change. American journal of pharmaceutical education, 72(2), 42.

Blouin, R. A., Riffee, W. H., Robinson, E. T., Beck, D. E., Green, C., Joyner, P. U., \& Pollack, G. M. (2009). Roles of innovation in education delivery. AJPE.

Bonney, K. M. (2015). Case study teaching method improves student performance and perceptions of learning gains. Journal of microbiology \& biology education, 16(1), 21.

Chan, S.-Y., Lam, Y. K., \& Ng, T. F. (2018). Student's perception on initial experience of flipped classroom in pharmacy education: Are we ready? Innovations in Education and Teaching International, 1-12.

Crookes, K., Crookes, P. A., \& Walsh, K. (2013). Meaningful and engaging teaching techniques for student nurses: A literature review. Nurse education in practice, 13(4), 239-243.

Davey, P. (2015). The flipped classroom: Motivating student nurses to learn independently. Athens Journal of Health, 2(4), $261-269$.

Diab, B. M., \& Abdel, K. M. (2016). The effect of using flipped classroom instruction on students' achievement in the new 2016 scholastic assessment test mathematics skills in the United Arab Emirates. Electronic Theses and Dissertations. Retrieved from https://scholarworks.uaeu.ac.ae/all_theses/364

Dickens, L., \& Watkins, K. (1999). Action research: Rethinking Lewin. Management Learning, 30(2), 127-140.

Efron, S. E., \& Ravid, R. (2013). Action research in education: A practical guide. Guilford Press.

El-Banna, M. M., Whitlow, M., \& McNelis, A. M. (2017). Flipping around the classroom: Accelerated Bachelor of Science in Nursing students' satisfaction and achievement. Nurse Education Today, 56, 41-46.

Erlingsson, C., \& Brysiewicz, P. (2017). A hands-on guide to doing content analysis. African Journal of Emergency Medicine, 7(3), 93-99.

Ferrance, E. (2000). Action research. LAB, Northeast and Island Regional Education Laboratory at Brown University.

Graneheim, U. H., \& Lundman, B. (2004). Qualitative content analysis in nursing research: Concepts, procedures and measures to achieve trustworthiness. Nurse Education Today, 24(2), 105-112.

Hanson, J. (2016). Surveying the experiences and perceptions of undergraduate nursing students of a flipped classroom approach to increase understanding of drug science and its application to clinical practice. Nurse Education in Practice, 16(1), 79-85.

Harrington, S. A., Bosch, M. V., Schoofs, N., Beel-Bates, C., \& Anderson, K. (2015). Quantitative outcomes for nursing students in a flipped classroom. Nursing Education Perspectives, 36(3), 179-181.

Herreid, C. F. (2007). Start with a story: The case study method of teaching college science. NSTA Press.

Herreid, C. F. (2011). Case study teaching. New directions for teaching and learning, 2011(128), 31-40.

Herreid, C. F., \& Schiller, N. A. (2013). Case studies and the flipped classroom. Journal of College Science Teaching, 42(5), 62-66.

Hessler, K. L. (2016). Nursing education: Flipping the classroom. The Nurse Practitioner, 41(2), 17-27.

Hung, H.-T. (2015). Flipping the classroom for English language learners to foster active learning. Computer Assisted Language Learning, 28(1), 81-96.

Johnston, A. N., Massa, H., \& Burne, T. H. (2013). Digital lecture recording: A cautionary tale. Nurse education in practice, 13(1), 40-47.

Jonassen, D. H., \& Hernandez-Serrano, J. (2002). Case-based reasoning and instructional design: Using stories to support problem solving. Educational Technology Research and Development, 50(2), 65-77.

Jwaifell, M., Abu-Omar, R., \& Al-Tarawneh, M. (2018). The readiness of Arabic language teachers for integrating flipped classroom: Case of Ma'an. International Journal of Instruction, 11(4), 855-868.

Karabulut-Ilgu, A., Cherrez, N. J., \& Hassall, L. (2018). Flipping to engage students: Instructor perspectives on flipping large enrolment courses. Australasian Journal of Educational Technology, 34(4).

Kemmis, S., McTaggart, R., \& Nixon, R. (2013). The action research planner: Doing critical participatory action research. Springer Science \& Business Media.

Khalil, R., Rania, M., \& Fahim, S. S. (2017). Assessment as a learning tool in a flipped English language classroom in higher education. Paper presented at the Arab World English Journal, December 2016 ASELS Annual Conference Proceedings.

Kumar, M. (2011). How to use role-play in teaching and training. Corporate training materials. com.

Mailloux, C. G. (2011). Using the essentials of baccalaureate education for professional nursing practice (2008) as a framework for curriculum revision. Journal of Professional Nursing, 27(6), 385-389.

McLaughlin, J. E., Roth, M. T., Glatt, D. M., Gharkholonarehe, N., Davidson, C. A., Griffin, L. M., \& Mumper, R. J. (2014). The flipped classroom: A course redesign to foster learning and engagement in a health professions school. Academic medicine, 89(2), 236-243.

Menegaz, J. d. C., Dias, G. A. R., Trindade, R. F. S., Leal, S. N., \& Martins, N. K. A. (2018). Flipped classroom in teaching nursing management: Experience report. Escola Anna Nery, 22(3).

Milman, N. B. (2012). The flipped classroom strategy: What is it and how can it best be used? Distance learning, 9(3), 85.

Missildine, K., Fountain, R., Summers, L., \& Gosselin, K. (2013). Flipping the classroom to improve student performance and satisfaction. Journal of Nursing Education, 52(10), 597-599.

Moch, S. D., Vandenbark, R. T., Pehler, S.-R., \& Stombaugh, A. (2016). Use of action research in nursing education. Nursing Research and Practice, 2016.

Nugent, G., Malik, S., \& Hollingsworth, S. (2012). A practical guide to action research for literacy educators. Retrieved December, 24, 2015.

Panicker, L. (2018). Experiences of flipping an online classroom: An appraisal using Community of Inquiry Framework. GSTF Journal of Nursing and Health Care (JNHC), 5(1).

Peisachovich, E. H., Murtha, S., Phillips, A., \& Messinger, G. (2016). Flipping the classroom: A pedagogical approach to applying clinical judgment by engaging, interacting, and collaborating with nursing students. International Journal of Higher Education, 5(4), 114-121.

Polit, D. F., \& Beck, C. T. (2008). Nursing research: Generating and assessing evidence for nursing practice. Lippincott Williams \& Wilkins. 
Richardson, M., Abraham, C., \& Bond, R. (2012). Psychological correlates of university students' academic performance: A systematic review and meta-analysis. Psychological bulletin, 138(2), 353.

Rocca, K. A. (2010). Student participation in the college classroom: An extended multidisciplinary literature review. Communication education, 59(2), 185-213.

Rodrigues, A., \& Zealand, W. (2016). Use of the flipped classroom model in the clinical learning curriculum for third year nursing students In H. In Paper presented at the Tetipuranga-Growing capability. Proceedings of the 2015 National Tertiary Learning and Teaching Conference.

Roehling, P. V., Root Luna, L. M., Richie, F. J., \& Shaughnessy, J. J. (2017). The benefits, drawbacks, and challenges of using the flipped classroom in an introduction to psychology course. Teaching of Psychology, 44(3), 183-192.

Ryan, A., \& Tilbury, D. (2013). Flexible pedagogies: new pedagogical ideas. London: Higher Education Academy.

Sojayapan, C., \& Khlaisang, J. (2018). The effect of a flipped classroom with online group investigation on students' team learning ability. Kasetsart Journal of Social Sciences.

Tan, C., Yue, W.-G., \& Fu, Y. (2017). Effectiveness of flipped classrooms in nursing education: Systematic review and metaanalysis. Chinese Nursing Research, 4(4), 192-200.

Tang, F., Chen, C., Zhu, Y., Zuo, C., Zhong, Y., Wang, N., et al. (2017). Comparison between flipped classroom and lecturebased classroom in ophthalmology clerkship. Medical education online, 22(1), 1395679.

Thistlethwaite, J. E., Davies, D., Ekeocha, S., Kidd, J. M., MacDougall, C., Matthews, P., et al. (2012). The effectiveness of casebased learning in health professional education. A BEME systematic review: BEME Guide No. 23. Medical Teacher, 34(6), e421-e444.

Towle, A., \& Breda, K. (2014). Teaching the millennial nursing student: Using a. Nursing and Health, 2(6), 107-114.

Tune, J. D., Sturek, M., \& Basile, D. P. (2013). Flipped classroom model improves graduate student performance in cardiovascular, respiratory, and renal physiology. Advances in physiology education, 37(4), 316-320.

Unal, Z., \& Unal, A. (2017). Comparison of student performance, student perception, and teacher satisfaction with traditional versus flipped classroom models. International Journal of Instruction, 10(4), 145-164.

Valiga, T. (2006). Why we need evidence-based teaching practices. Teaching evidence-based practice in nursing: A guide for academic and clinical settings, 261-274.

Wagner, B. (2018). The effects of a flipped classroom on student comprehension and perception among second language learners in a bachelor of social work course.

Wallace, A. (2013). Social learning platforms and the flipped classroom. Paper presented at the 2013 Second International Conference on E-Learning and E-Technologies in Education (ICEEE).

Yadav, A., Lundeberg, M., DeSchryver, M., Dirkin, K., Schiller, N. A., Maier, K., \& Herreid, C. F. (2007). Teaching science with case studies: A national survey of faculty perceptions of the benefits and challenges of using cases. Journal of College Science Teaching, 37(1), 34.

\section{Publisher's Note}

Springer Nature remains neutral with regard to jurisdictional claims in published maps and institutional affiliations.

\section{Submit your manuscript to a SpringerOpen ${ }^{\circ}$ journal and benefit from:}

- Convenient online submission

- Rigorous peer review

- Open access: articles freely available online

High visibility within the field

- Retaining the copyright to your article

Submit your next manuscript at $\mathbf{s p r i n g e r o p e n . c o m ~}$ 